\title{
Plasmonic and Superhydrophobic Self-Decontaminating N95 Respirators
}

Hong Zhong ${ }^{1}$, Zhaoran Zhu ${ }^{1}$, Peng You$^{2}$, Jing Lin ${ }^{1}$, Chi Fai Cheung 1 , Vivien L. Lu Feng Yan ${ }^{2}$, Ching-Yuen Chan ${ }^{1}$, Guijun $\mathrm{Li}^{1 *}$

${ }^{1}$ State Key Laboratory of Ultra-Precision Machining Technology, Department of Industrial and Systems Engineering, The Hong Kong Polytechnic University, Kowloon, Hong Kong, 999077, China

${ }^{2}$ Department of Applied Physics, The Hong Kong Polytechnic University, Kowloon, Hong Kong, 999077, China

${ }^{3}$ Department of Building Services Engineering, The Hong Kong Polytechnic University, Kowloon, Hong Kong, 999077, China

Email: mitchli@ieee.org 


\section{Supporting figures}

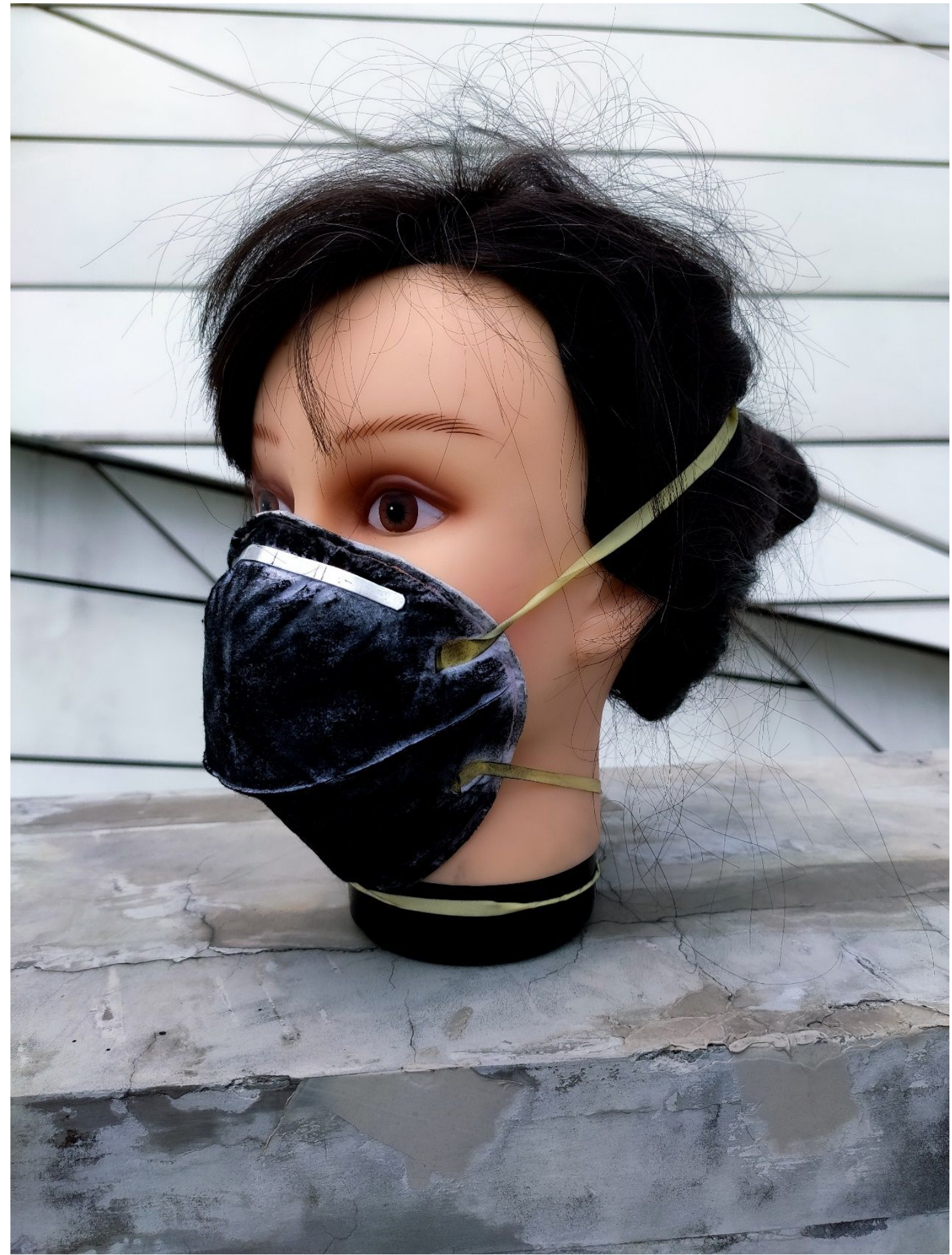

Figure S1. Optical photo image of the M2 N95 respirator. 


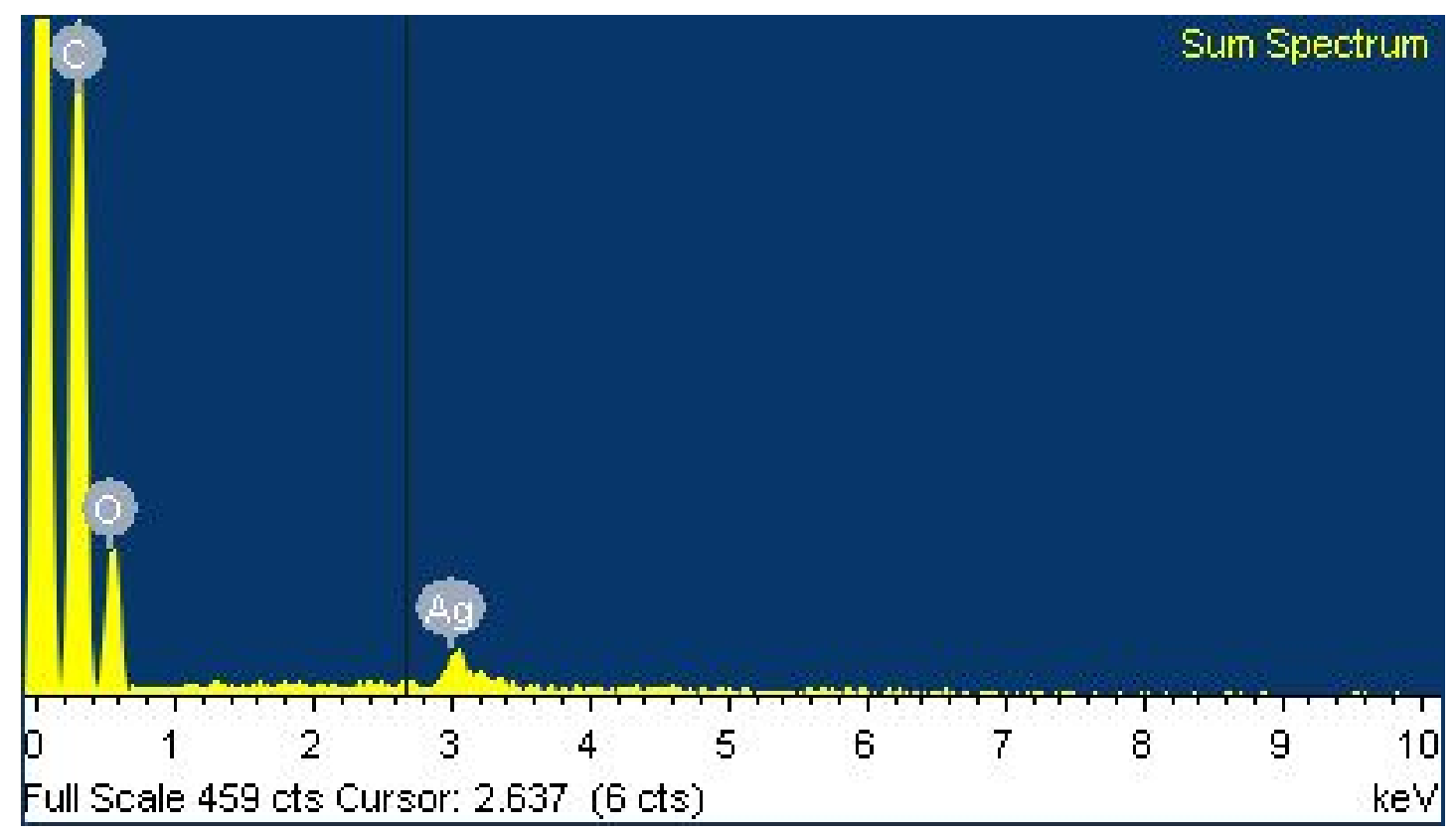

\begin{tabular}{l|ll}
\hline Element & Weight\% & Atomic\% \\
C K & 67.60 & 75.74 \\
Cu K & 28.22 & 23.74 \\
Ag L & 4.18 & 0.52 \\
& & \\
Totals & 100.00 & \\
\hline
\end{tabular}

Figure S2. EDX of M1 coating on N95 respirators. 
(a)

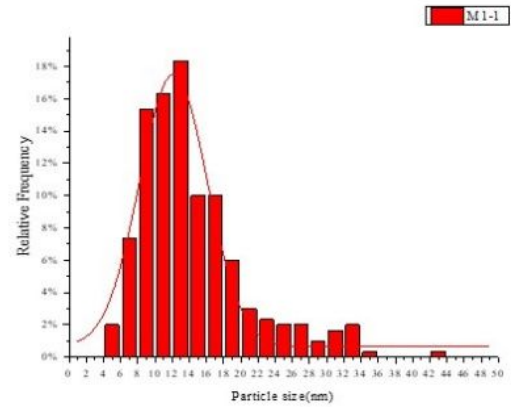

(b)

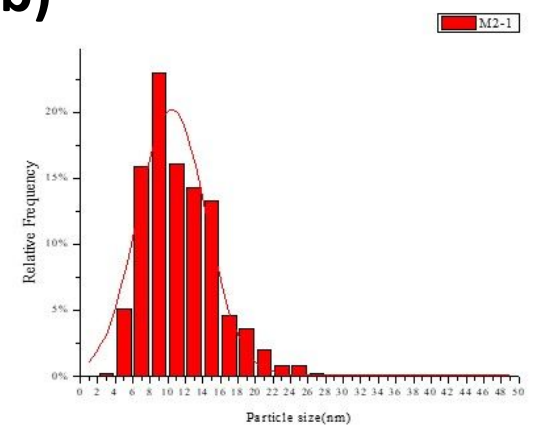

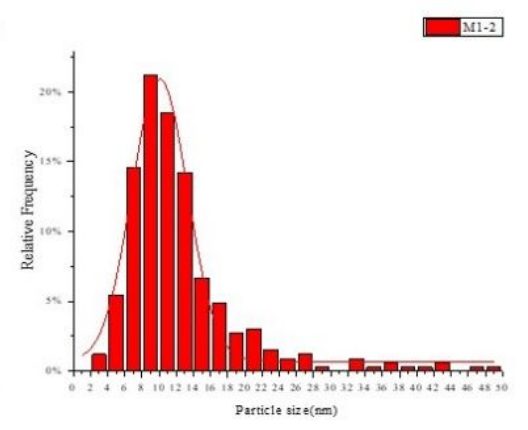

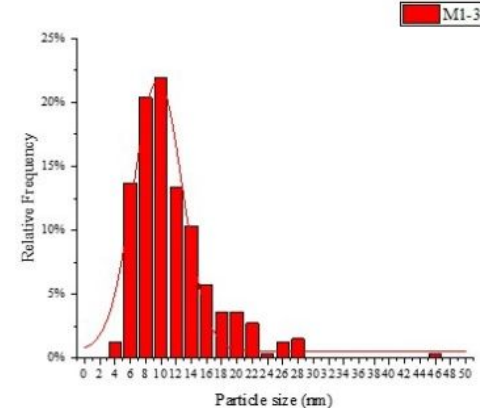

Particle size (rm)

\begin{tabular}{c|c|c|c||c|c|c} 
& \multicolumn{3}{|c||}{ M1(Figure S3a) } & \multicolumn{3}{c}{ M2(Figure S3b) } \\
\hline Sample & M1-1 & M1-2 & M1-3 & M2-1 & M2-2 & M2-3 \\
\hline Average (nm) & 14.42643 & 12.56773 & 11.9945 & 11.39875 & 12.24861 & 10.67149 \\
\hline Variance & 40.35796 & 49.25208 & 31.16613 & 17.15694 & 20.48728 & 19.34458
\end{tabular}

Figure S3. Particle size distribution of samples. (a) M1 samples. (b) M2 samples. 

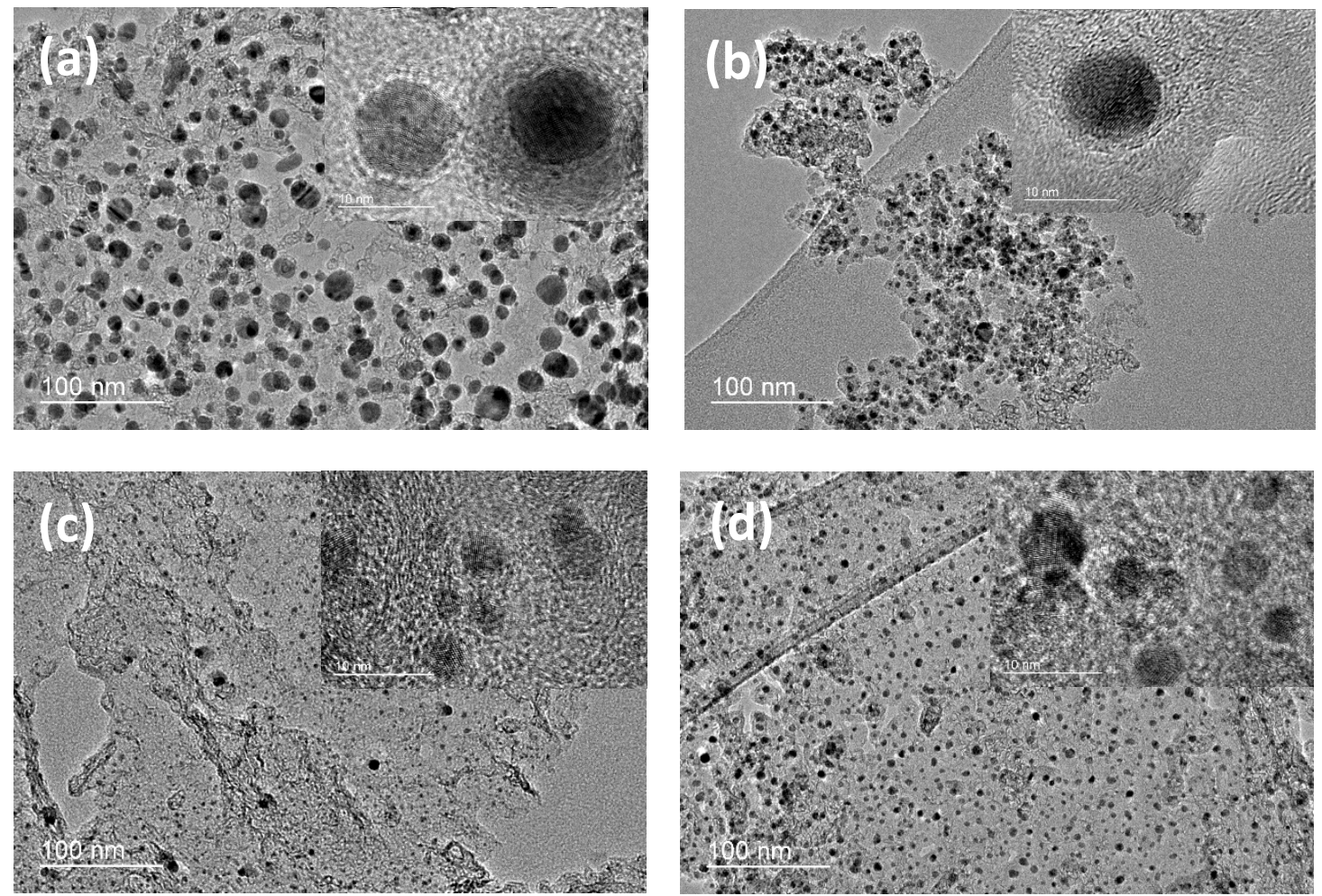

Figure S4. TEM images for the size distributions of the nanoparticles manufactured by M2, with different thicknesses of the precursor films and pulse laser powers after CW laser transfer. (a) $50 \mathrm{~nm} 3 \mathrm{~W} 400 \mathrm{~mm} / \mathrm{s}$ in CW mode and $0.5 \mathrm{~W} 400 \mathrm{~mm} / \mathrm{s}$ in pulse mode. (b) $50 \mathrm{~nm} 3 \mathrm{~W} 400 \mathrm{~mm} / \mathrm{s}$ in CW mode and $3 \mathrm{w} 400 \mathrm{~mm} / \mathrm{s}$ in pulse mode. (c) $20 \mathrm{~nm} 3 \mathrm{~W} 400 \mathrm{~mm} / \mathrm{s}$ in CW mode and $0.5 \mathrm{~W} 400 \mathrm{~mm} / \mathrm{s}$ in pulse mode. (d) $20 \mathrm{~nm}$ $3 \mathrm{~W} 400 \mathrm{~mm} / \mathrm{s}$ in CW mode and $3 \mathrm{~W} 400 \mathrm{~mm} / \mathrm{s}$ in pulse mode. 


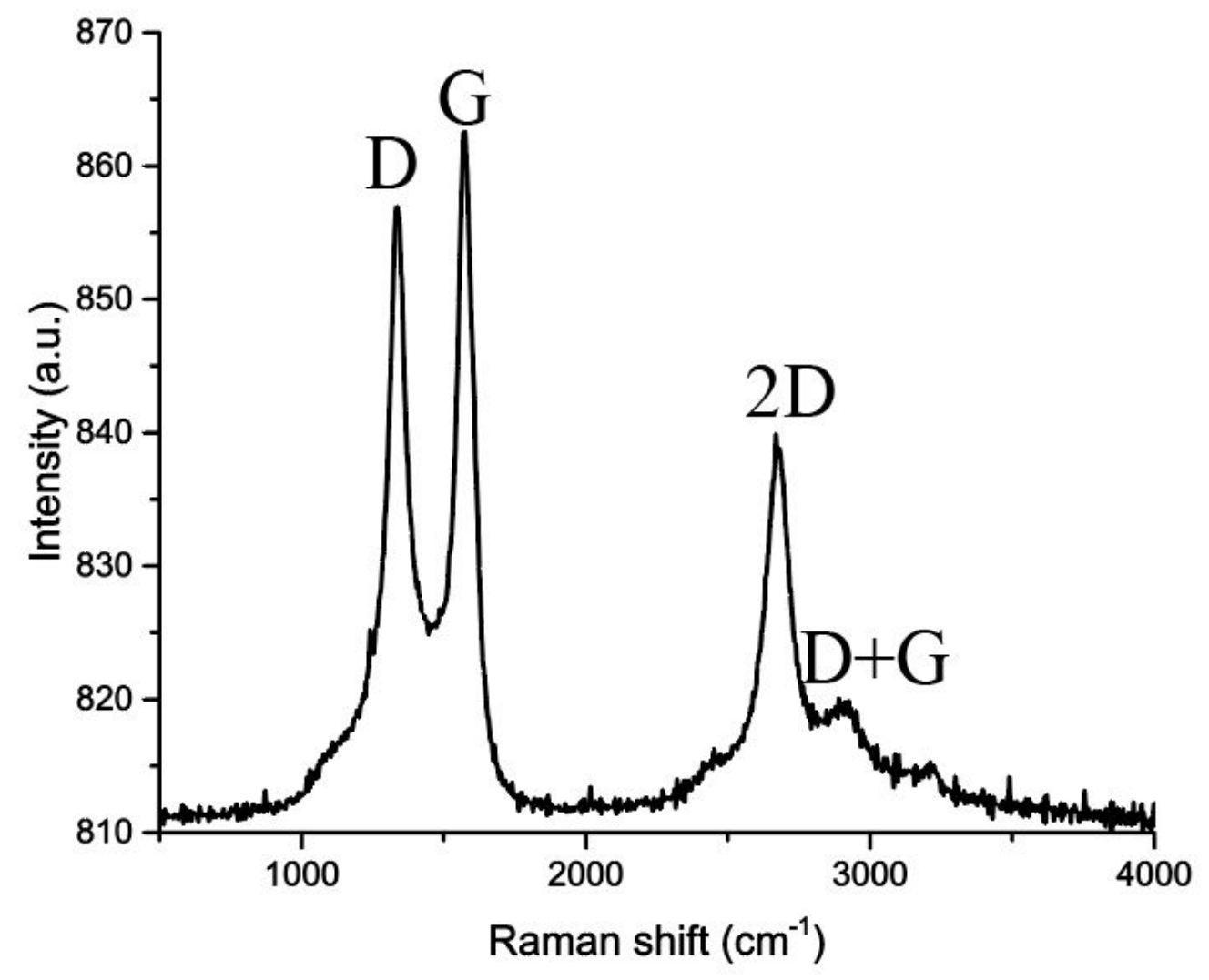

Figure S5. Raman characterization of the M2 respirators. 


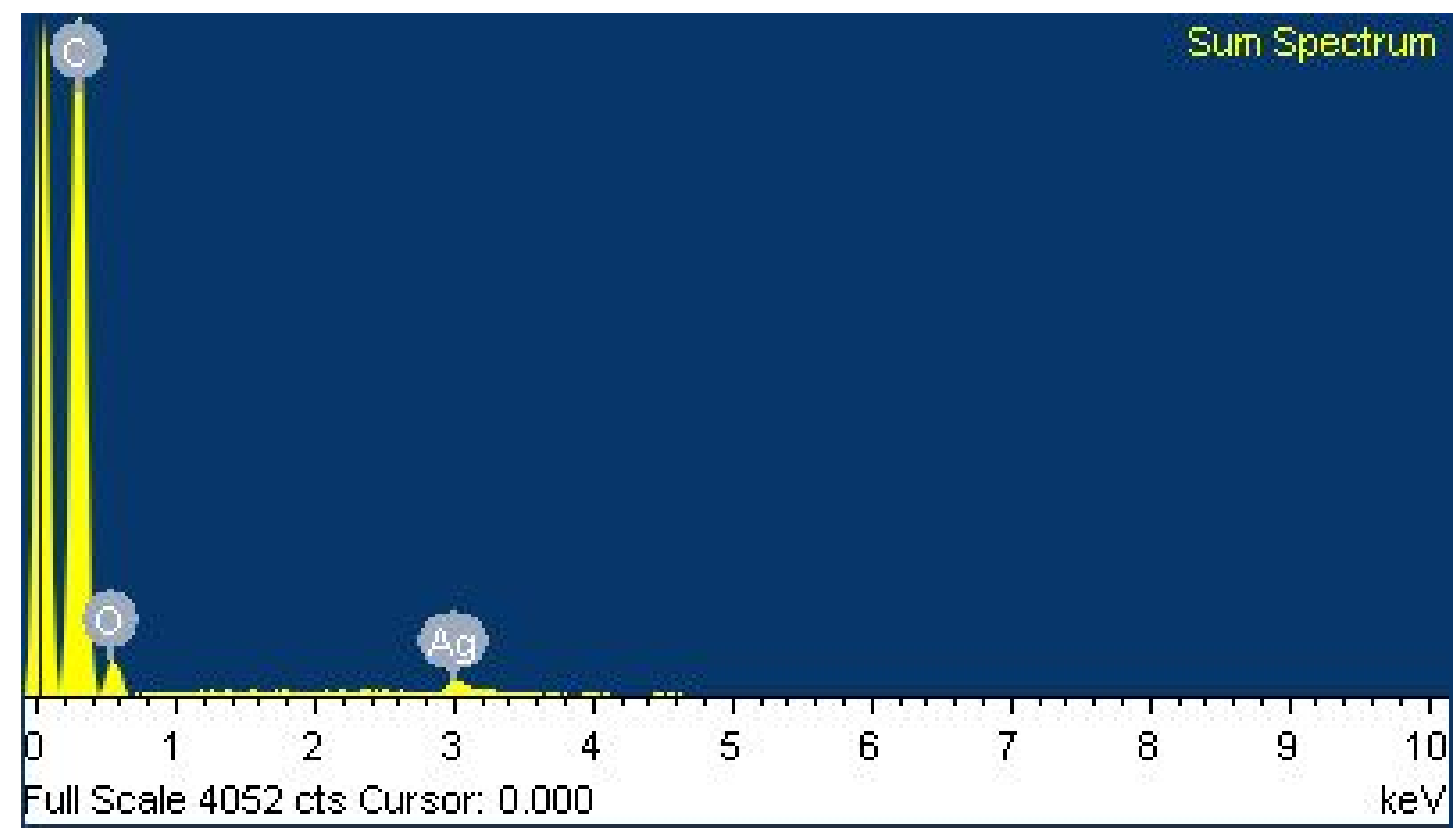

\begin{tabular}{l|ll}
\hline Element & Weight\% & Atomic\% \\
C K & 89.45 & 93.27 \\
O K & 8.26 & 6.46 \\
$\mathrm{Ag} \mathrm{L}$ & 2.29 & 0.27 \\
& & \\
Totals & 100.00 & \\
\hline
\end{tabular}

Figure S6. EDX of M2 coating on N95 respirator. 

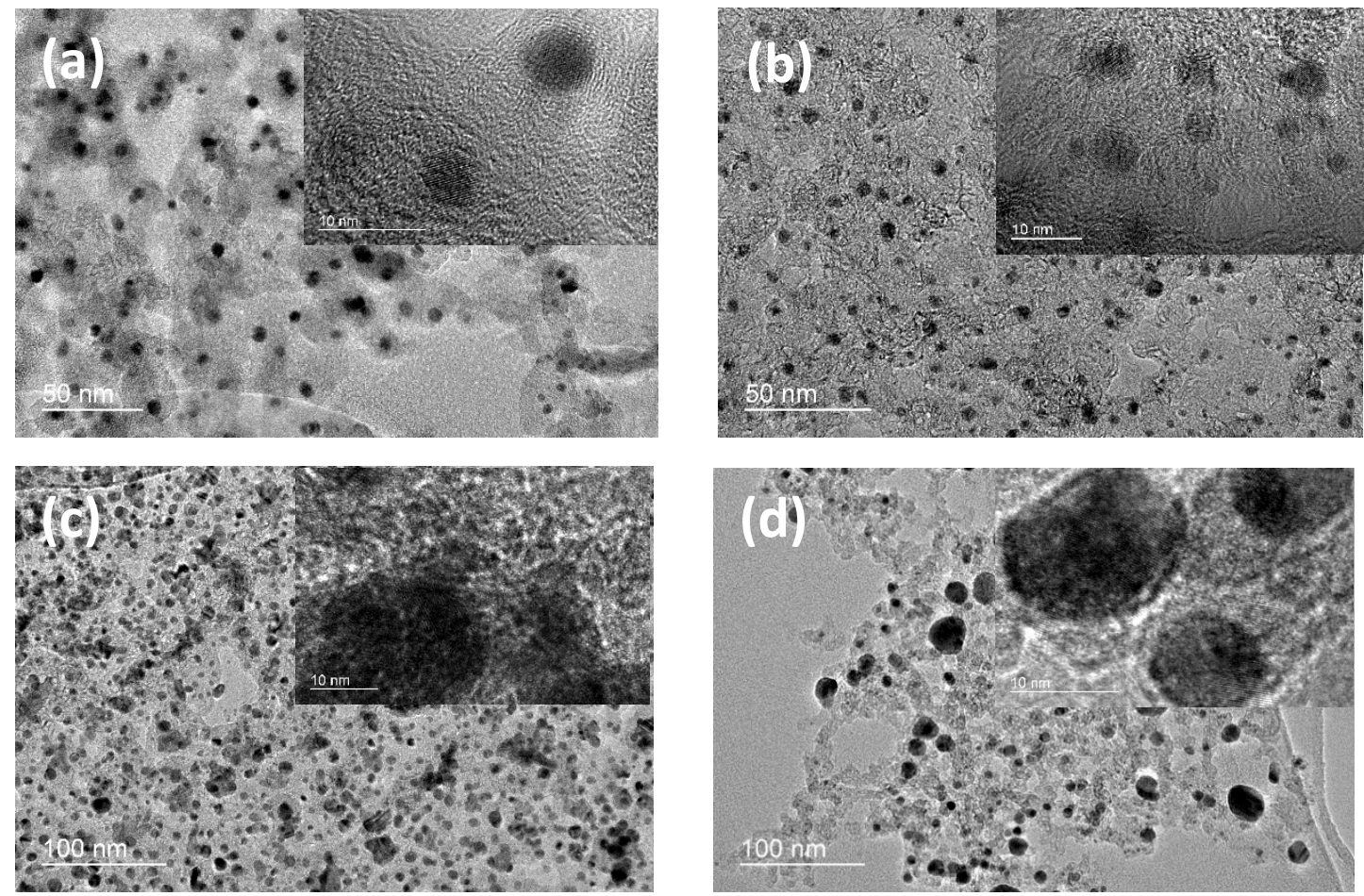

Figure S7. TEM images indicating the size distributions of the nanoparticles under

CW laser beam, with (a) $10 \mathrm{~nm}$ (b) $20 \mathrm{~nm}$ (c) $50 \mathrm{~nm}$ (d) $100 \mathrm{~nm}$ thickness of the precursor film. 

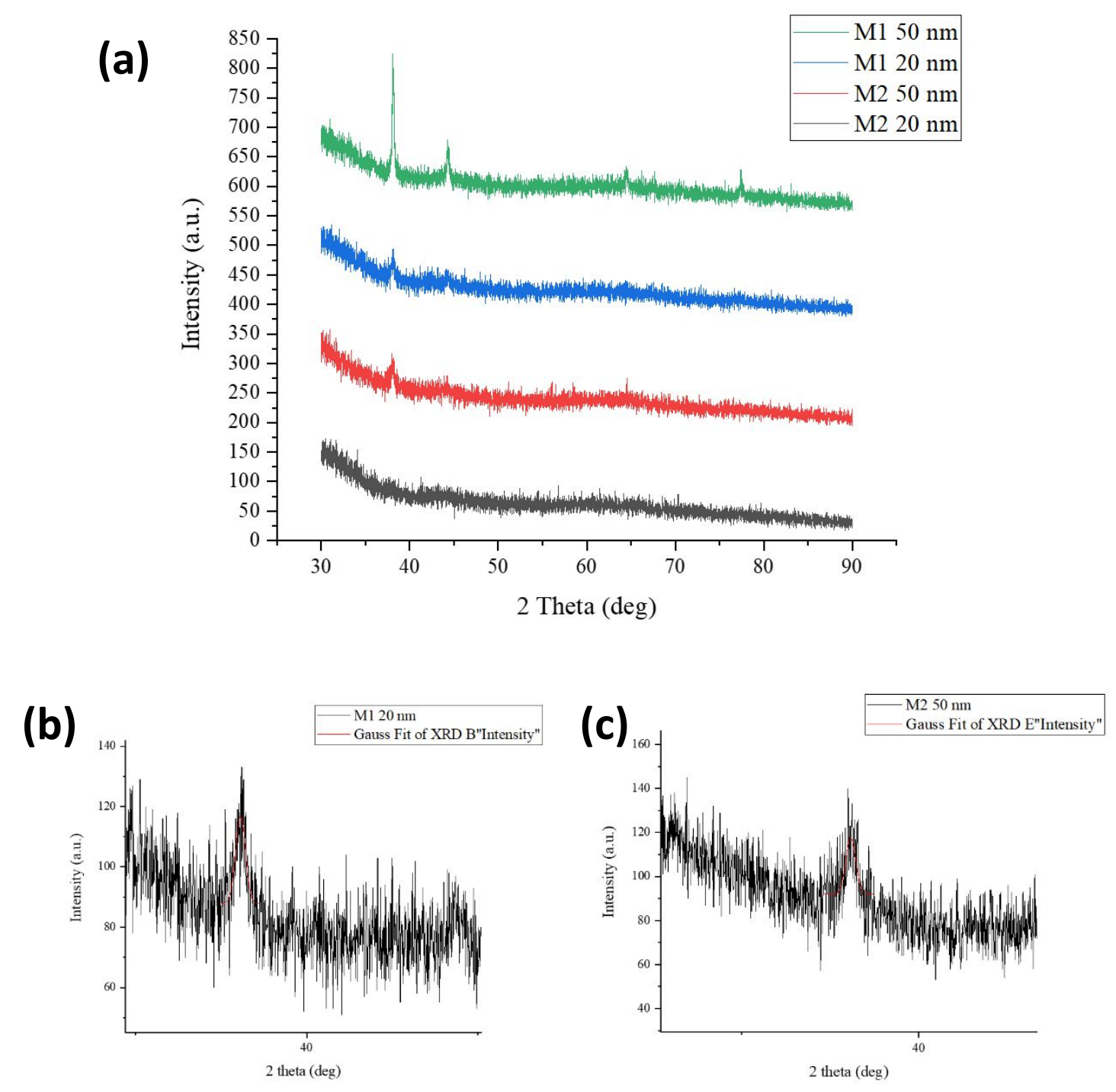

\begin{tabular}{c|c|c} 
& M1(Figure S8b) & M2(Figure S8c) \\
\hline FWHM & 0.33665 & 0.33615
\end{tabular}

Figure S8. X-ray diffraction (XRD) images for (a)different thicknesses of the precursor silver film. Half width measurement of (b)M1 sample with $20 \mathrm{~nm}$ thickness precursor. (c) M2 sample with $50 \mathrm{~nm}$ thickness precursor. 


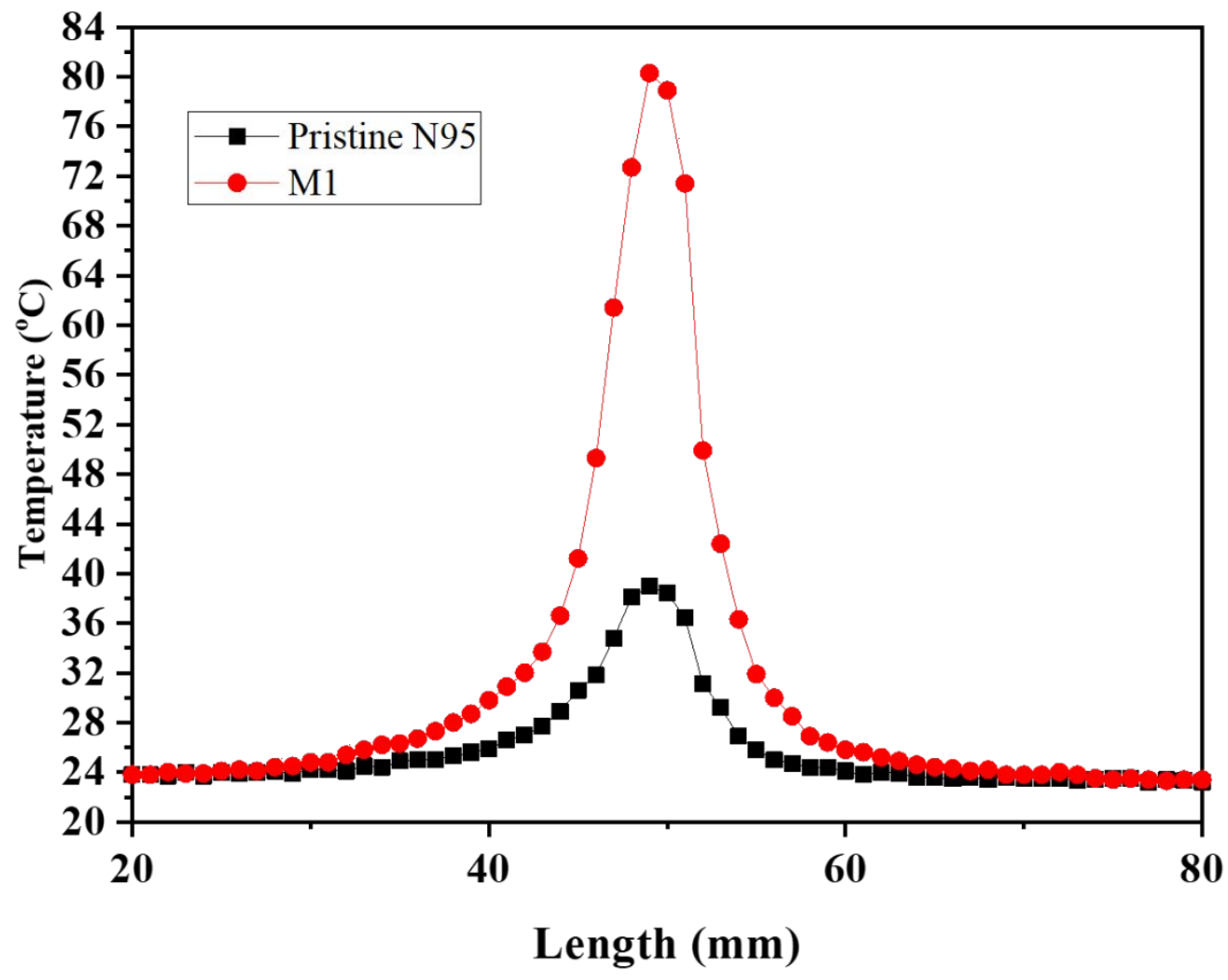

Figure S9. Temperature against laser width profile of the $405 \mathrm{~nm}$ laser heating with same power on M1 coated N95 respirator and the pristine mask, respectively. 

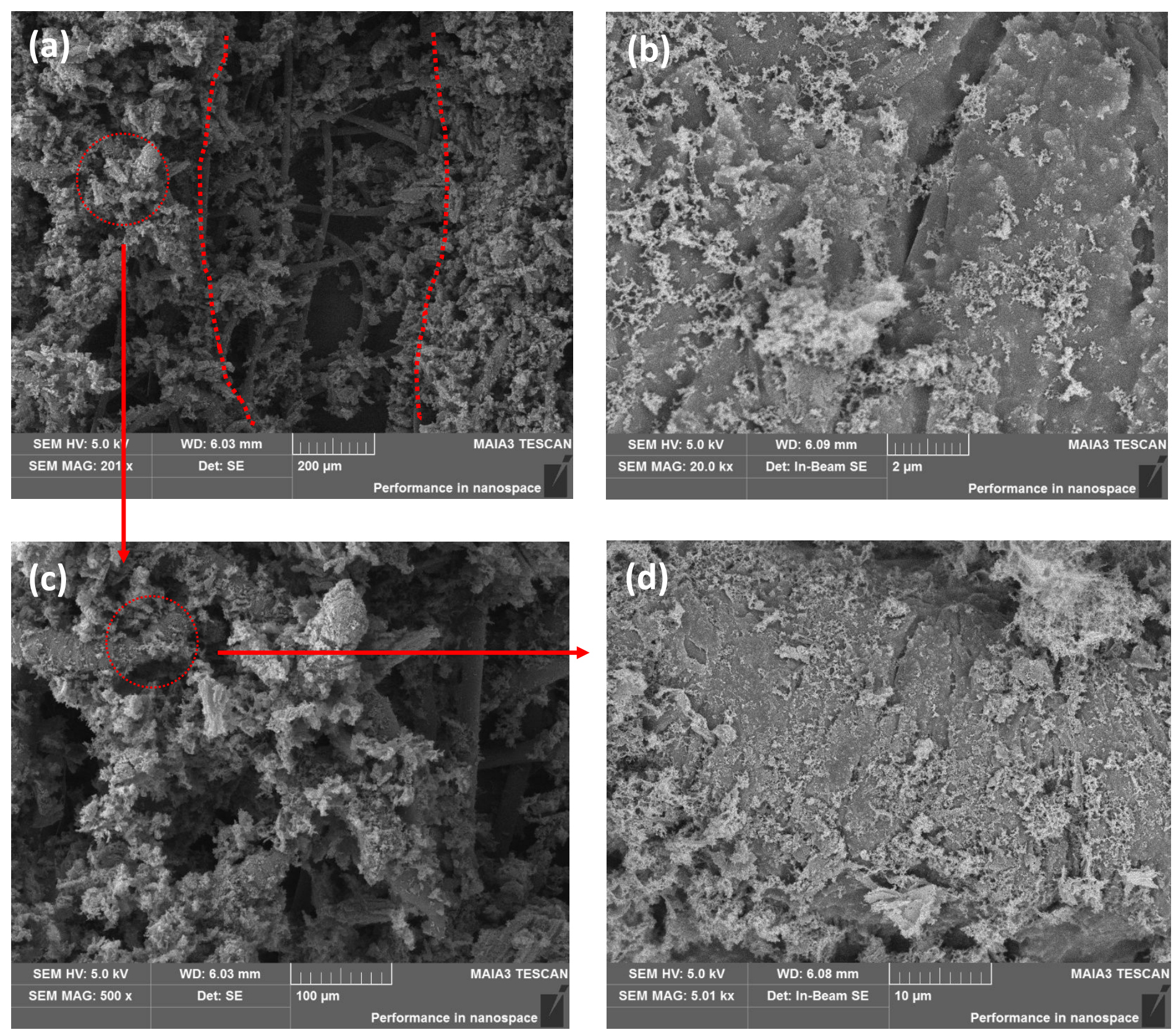

Figure S10. SEM images of the broken fibre under $125^{\circ} \mathrm{C}$ decontamination using 405

nm laser diode. 

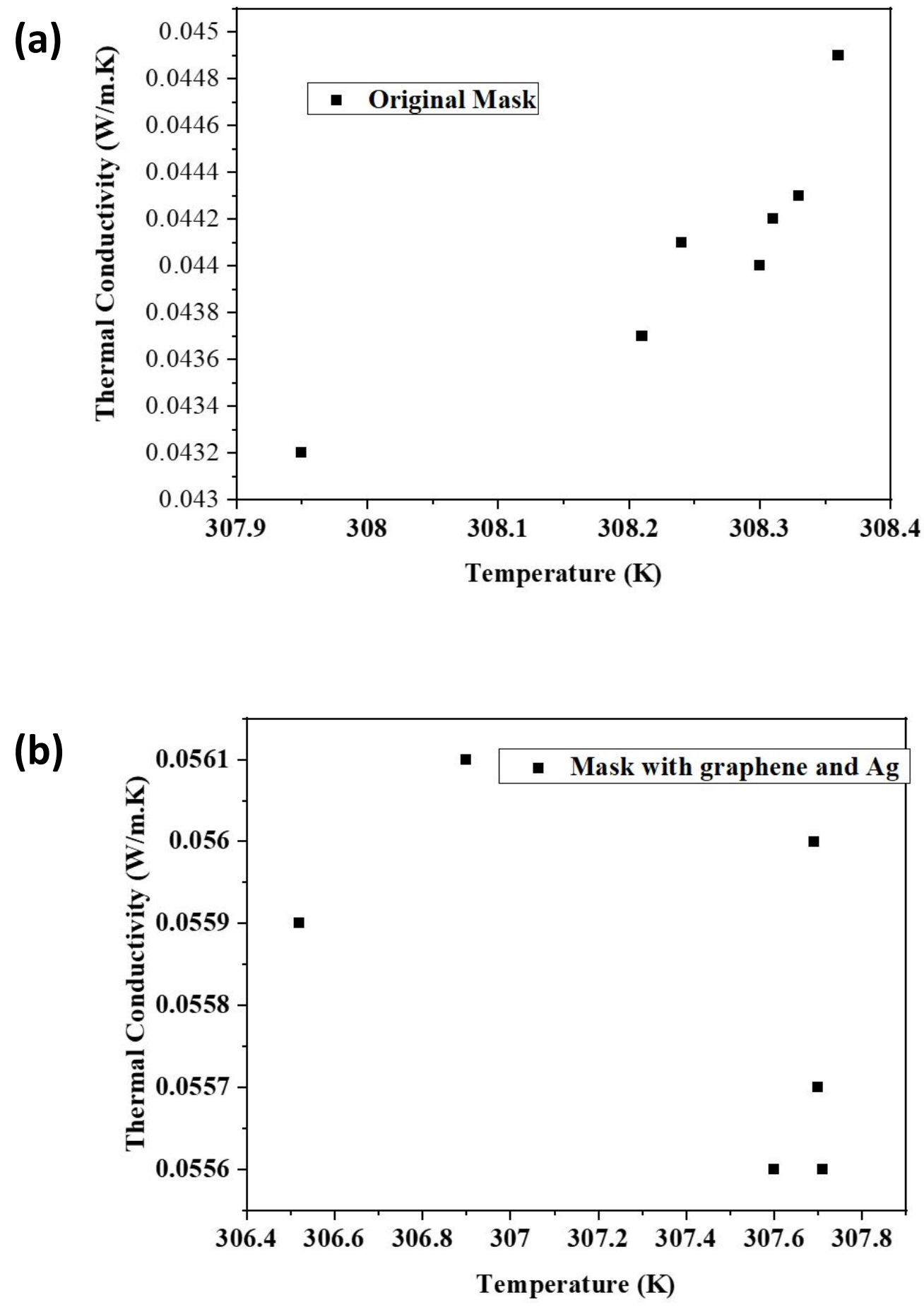

Figure S11. Thermal conductivity test for (a) Pristine mask. (b) Plasmonic composite coated mask. 


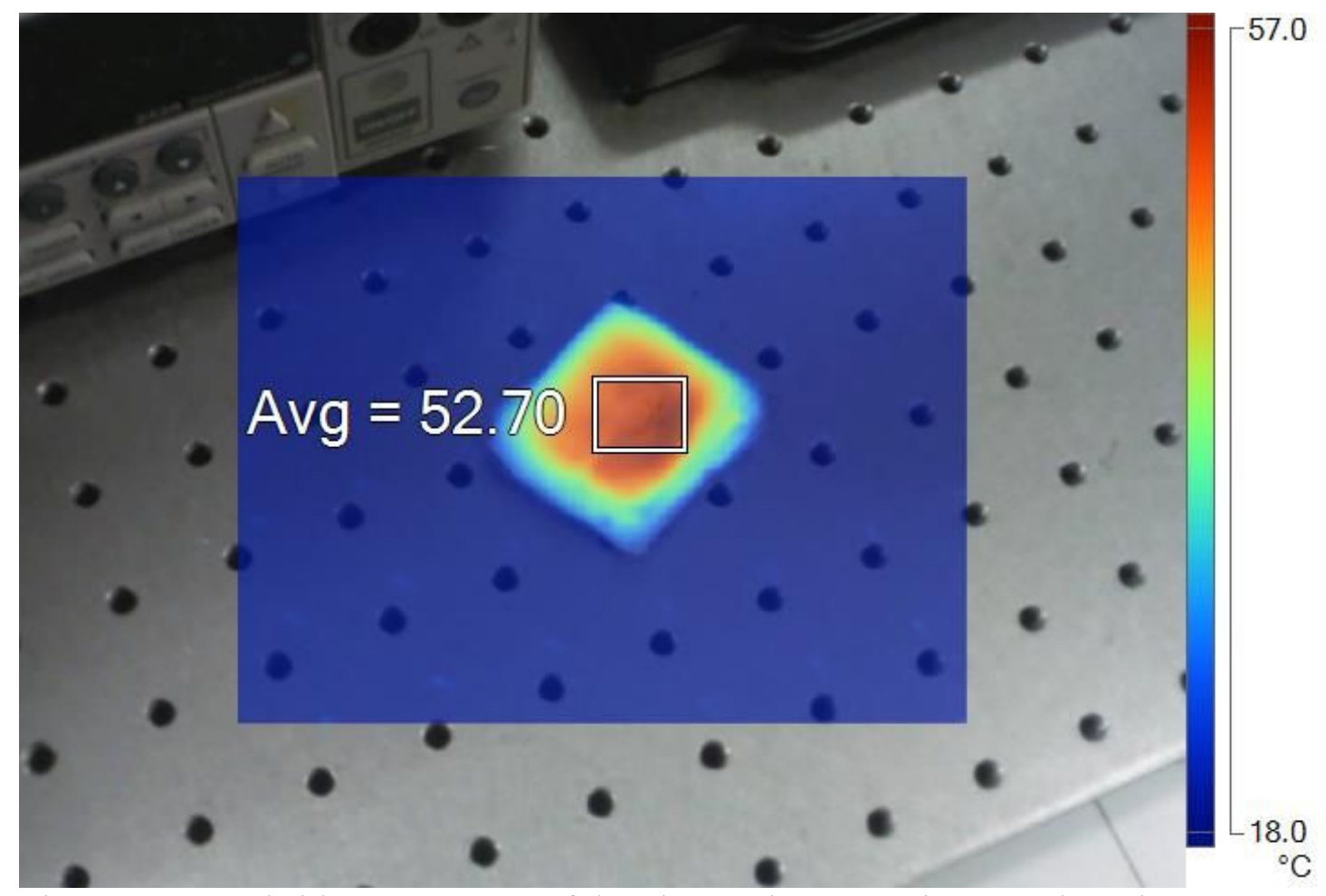

Figure S12. Backside temperature of the plasmonic composite coated mask. 


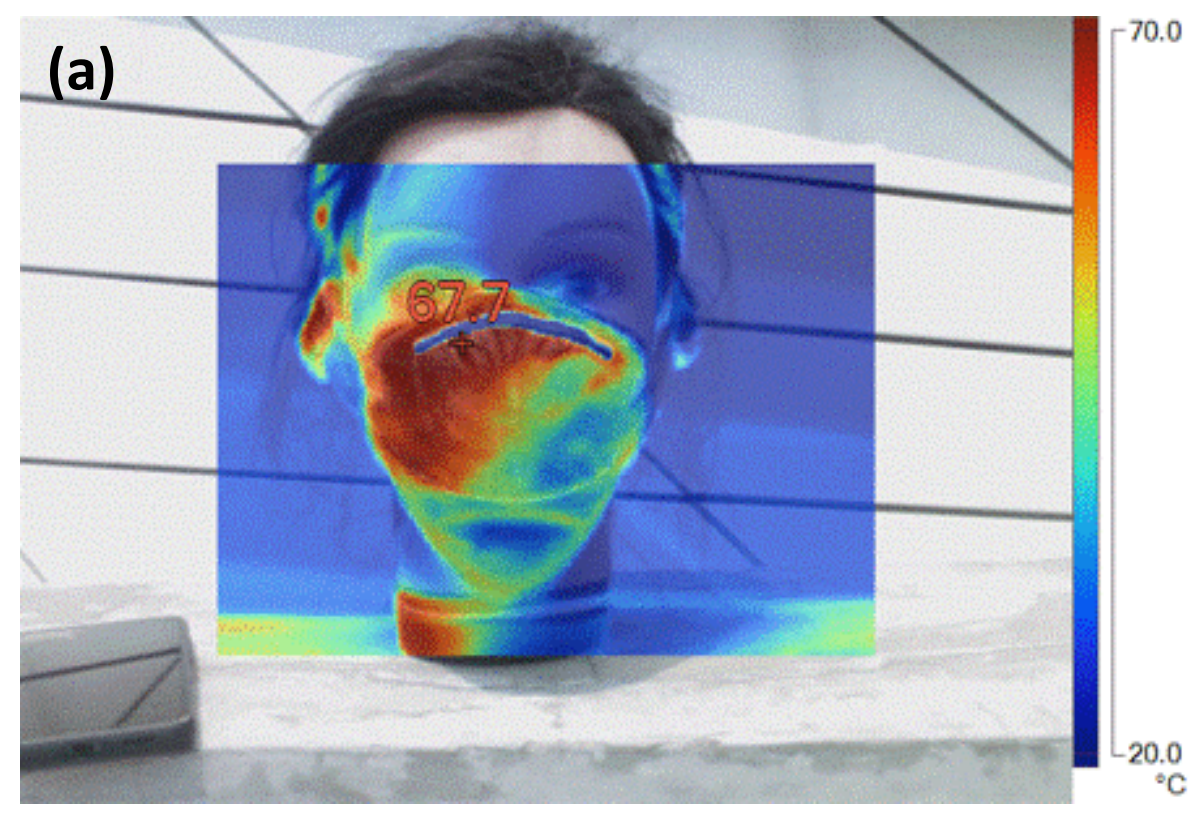

(b)

Direct Solar Radiation and Diffuse Solar Radiation

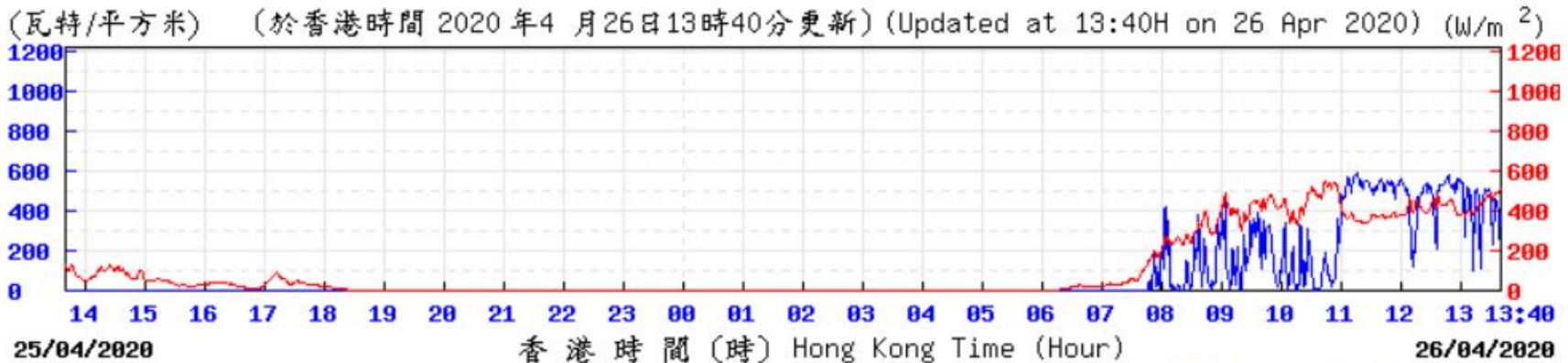

(C) 青㴽天文公 Hong Kong Observatory

Figure S13. Outdoor in-site test. (a) Infrared photo for respirators under sunshine. (b)

Real-time sun radiation, Hong Kong, 26 Apr 2020. 


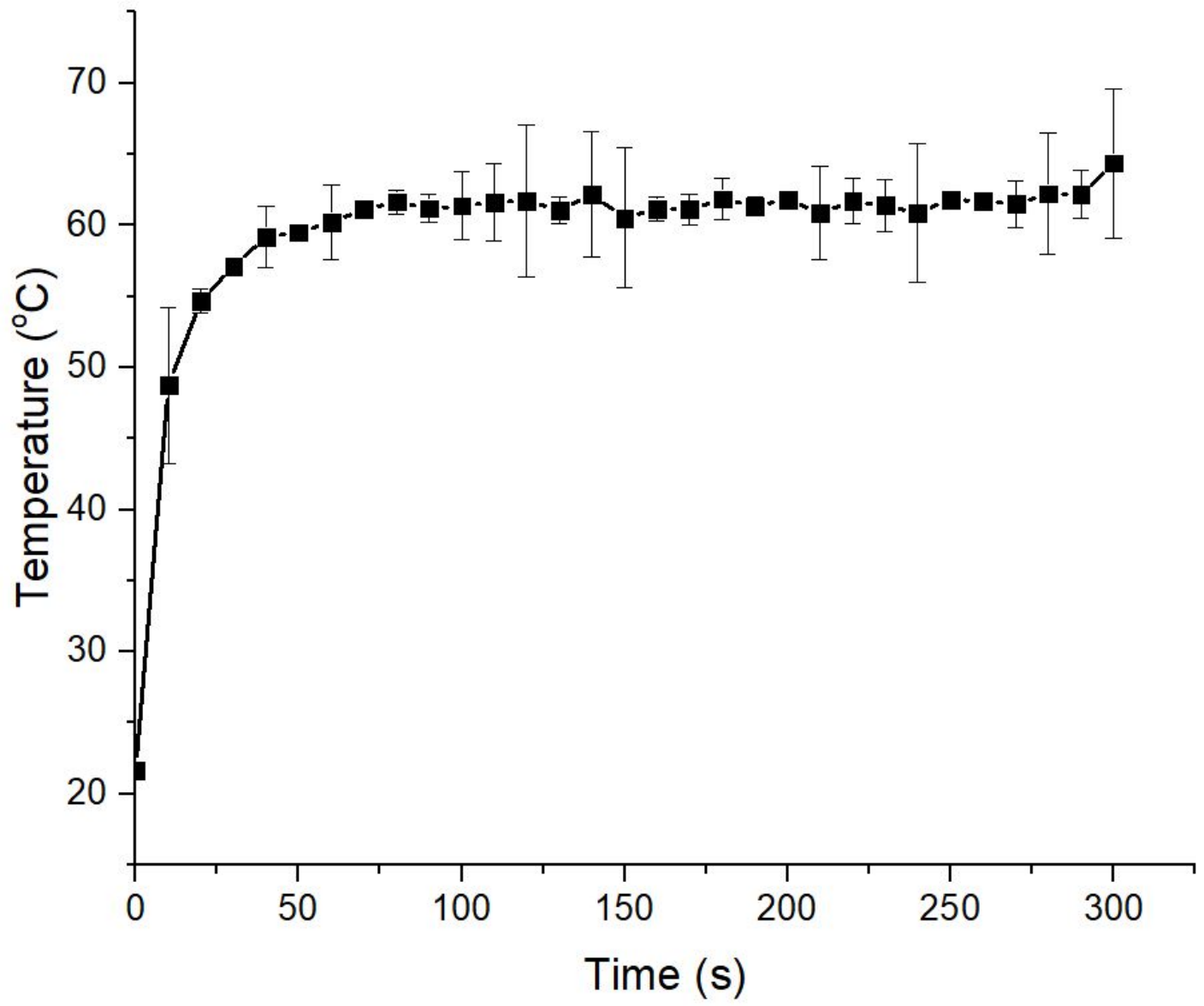

Figure S14. The temperature and time relationship of M2 respirator under $60 \%$ intensity of sunlight. 


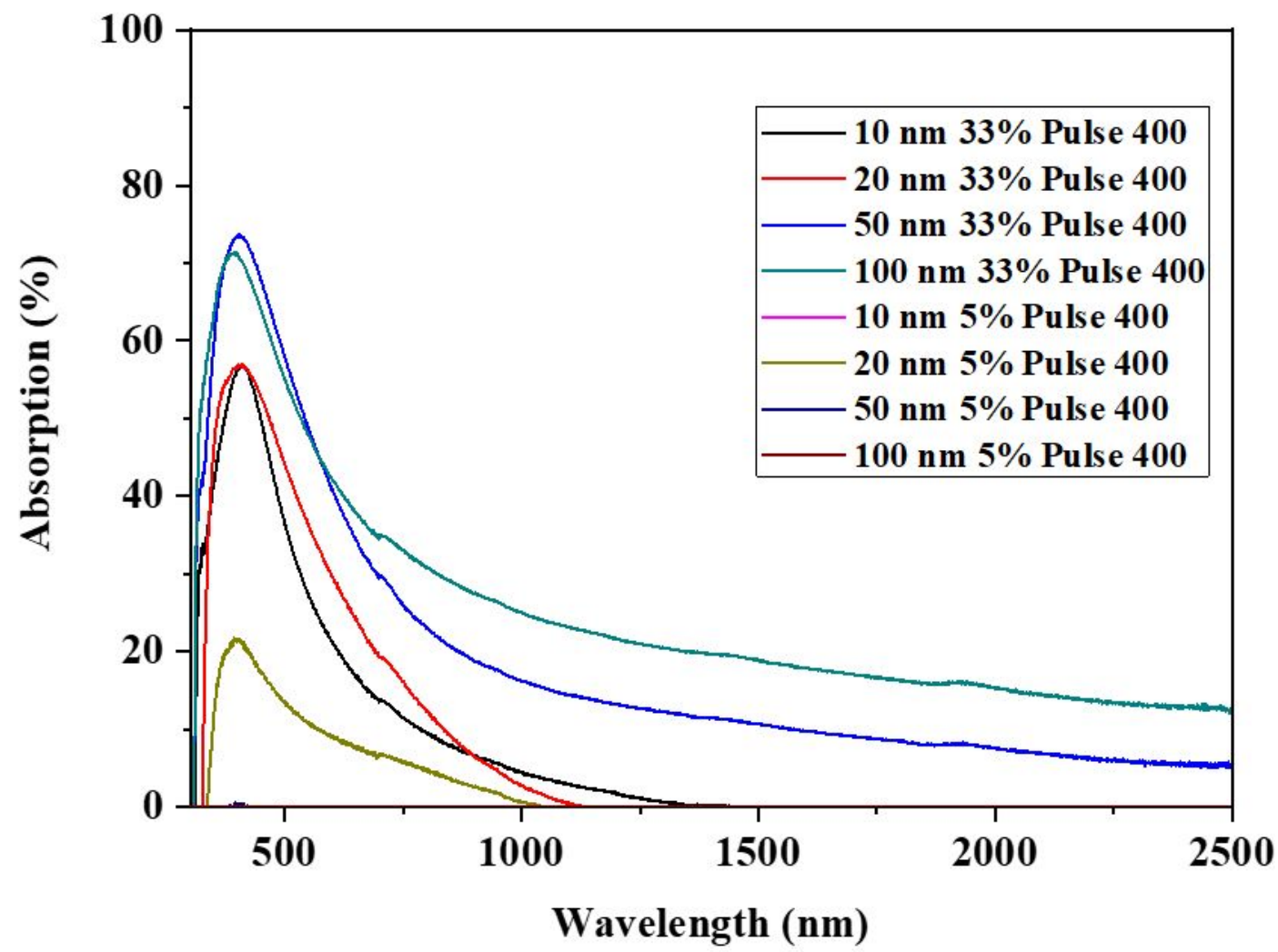

Figure S15. The optical absorption of different mode of laser printing on glass substrates, to study the plasmonic enhancements of different sizes of silver nanoparticles. 

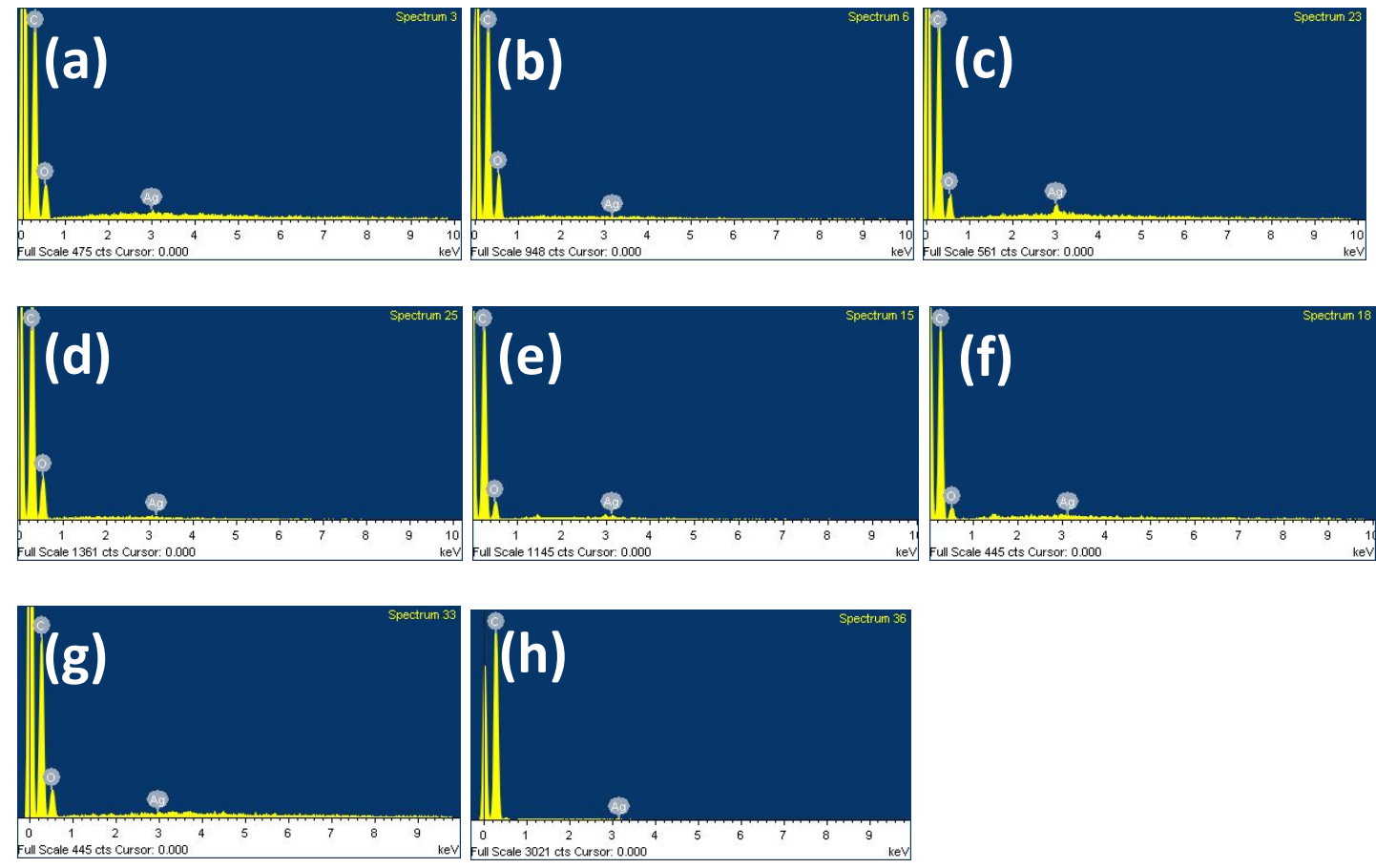

(i)
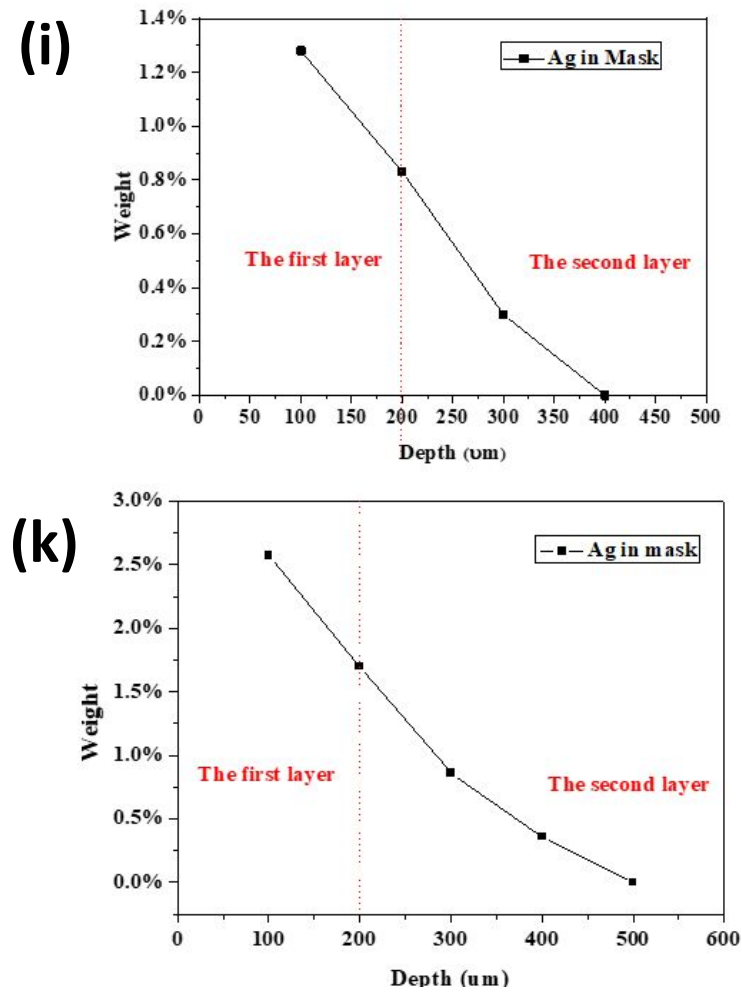

(j)

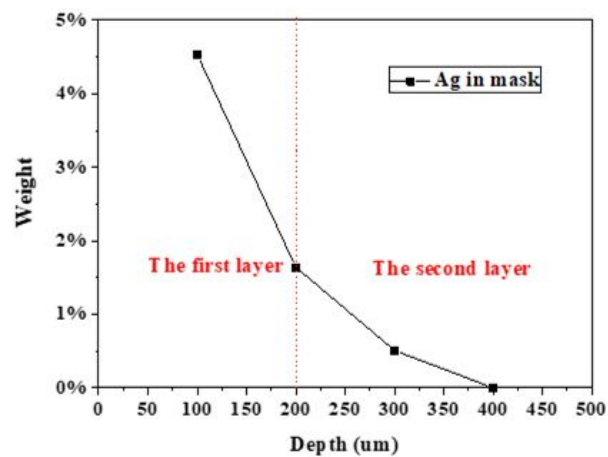

(I)

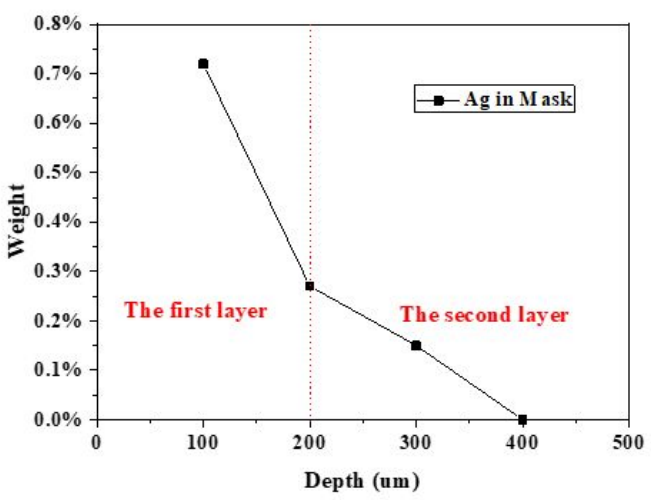

Figure S16. EDX of the silver particles in $(a, b)$ Sample 1. (c,d) Sample 2. (e,f) Sample 3 (g,h,) Sample 4 for the first layer $(100 \mu \mathrm{m})$ and second layer $(300 \mu \mathrm{m})$ accordingly.

Ag element weighting analysis for (i) Sample 1. (j) Sample 2. (k) Sample 3. (l)

Sample 4. 


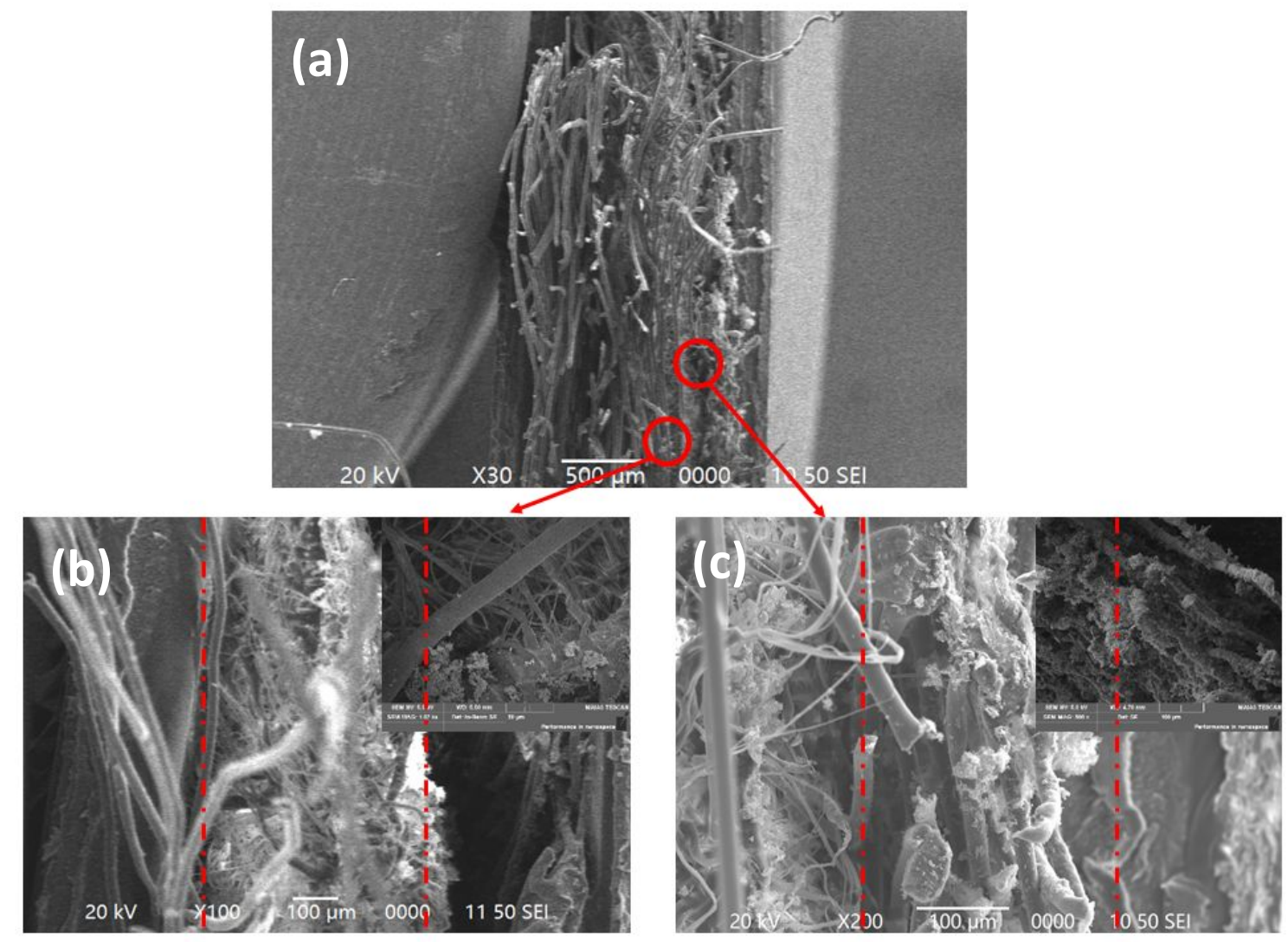

Figure S17. SEM images of the plasmonic composite (Ag-Graphene) coated mask. (a)

Sideview of the mask. (b) Middle layer with around $400 \mu \mathrm{m}$ thickness. (c) Outer layer with around $200 \mu \mathrm{m}$ thickness. 


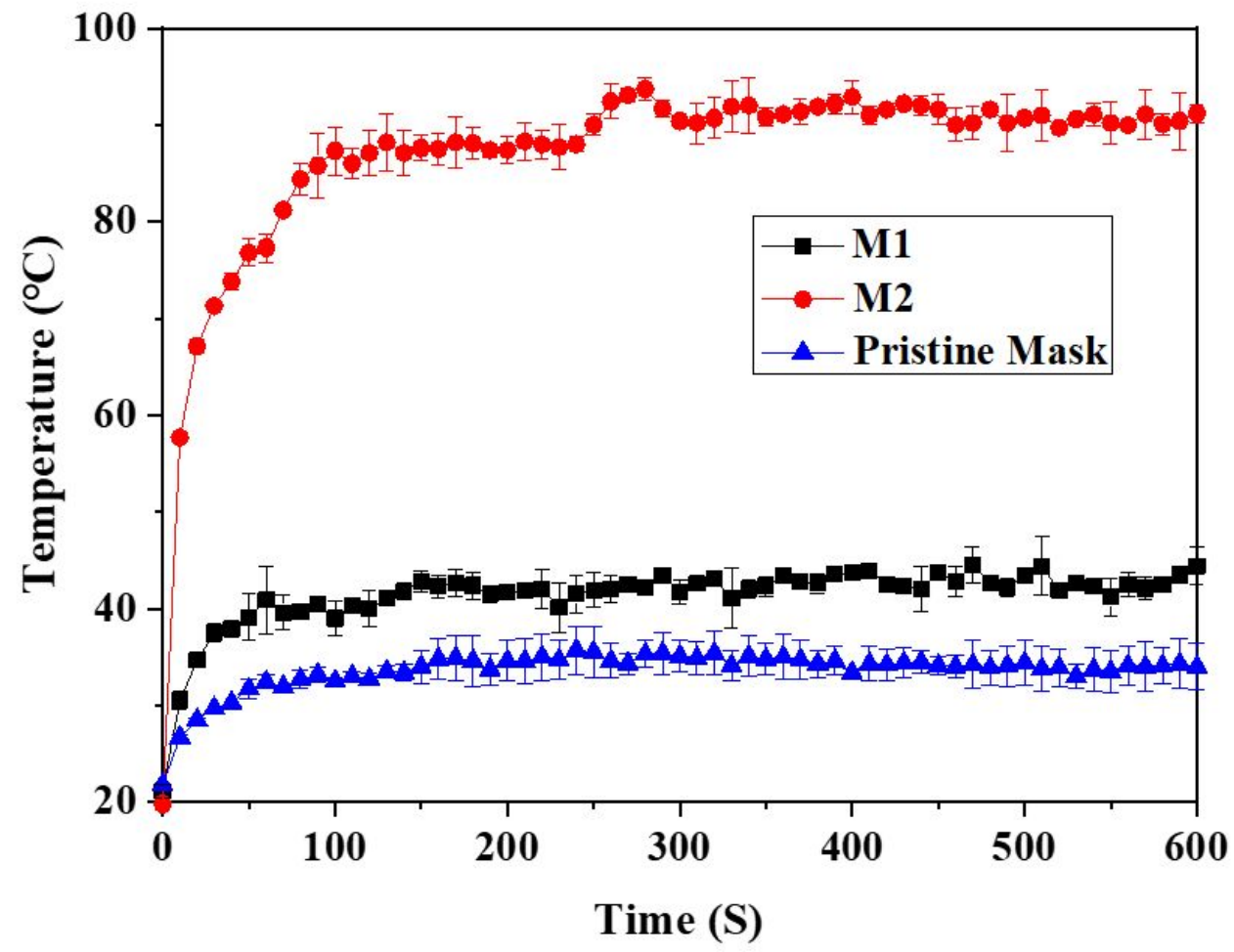

Figure S18. Result of backside temperature measured after 10 min of 1 sun intensity illumination. 


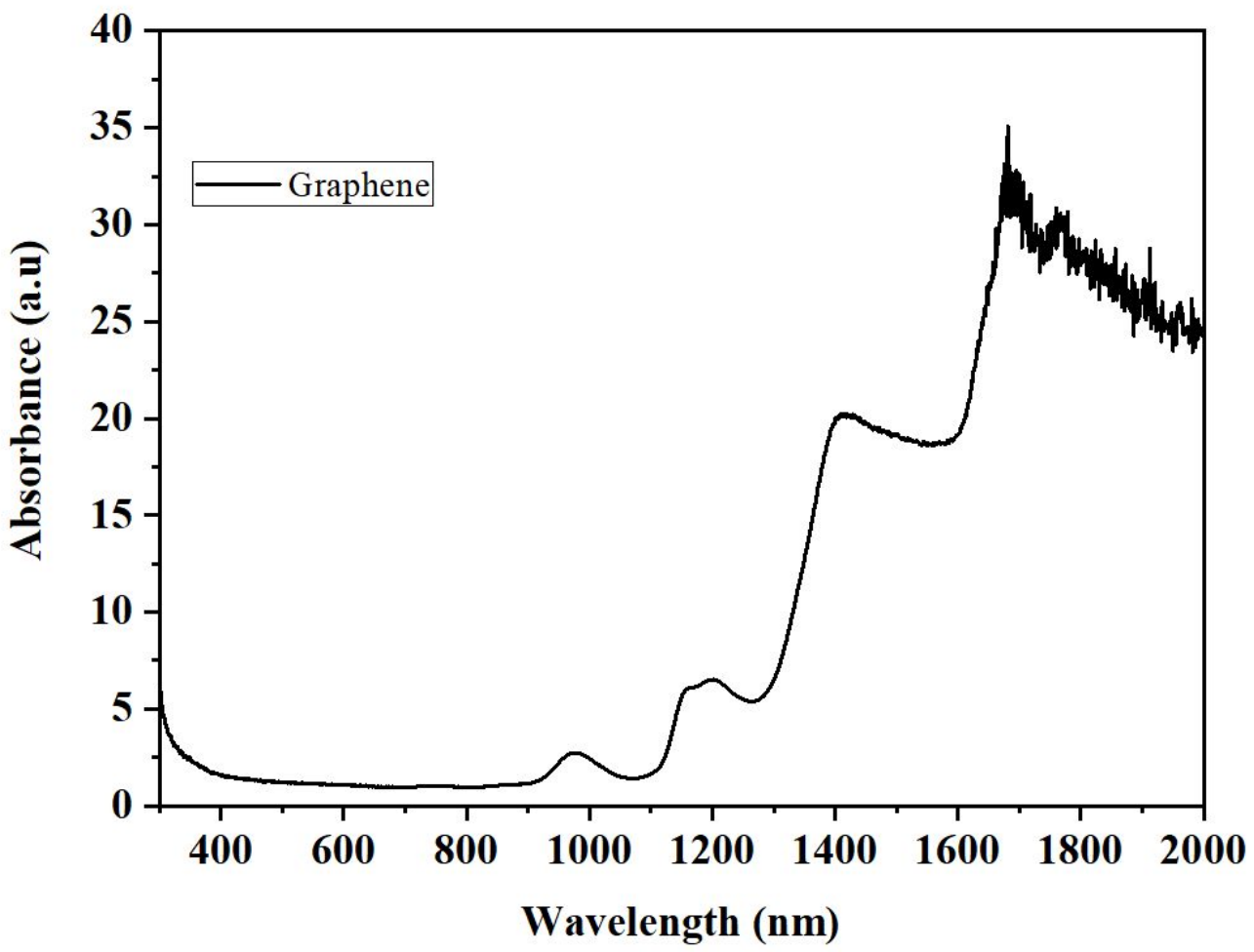

Figure S19. Absorbance of the mask with only laser induced transfer graphene coating. 

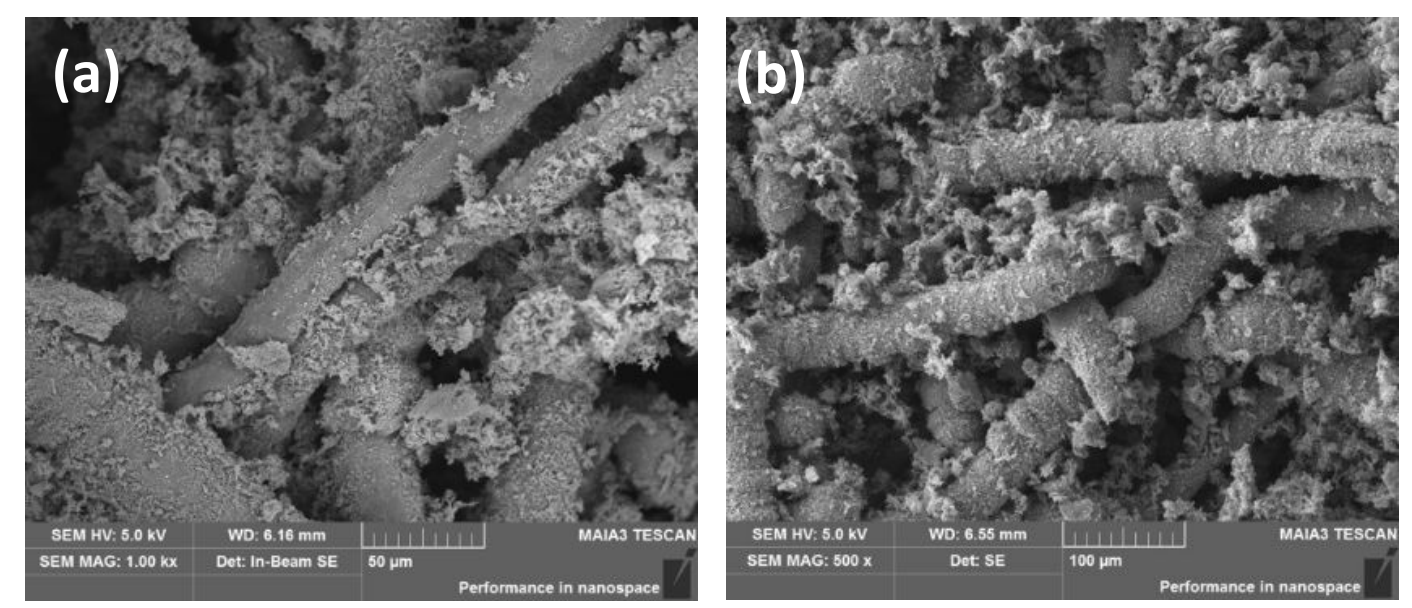

Figure S20. SEM images of the plasmonic composite coating for (a) new produced samples. (b) aging test after $72 \mathrm{~h}$ solar illumination. 